\title{
Conceptualizing an Afrocentric-Indigenous Pedagogy for an Inclusive Classroom Environment
}

\author{
Micheal M van Wyk \\ Department of Curriculum and Instructional Studies, \\ School of Teacher Education, College of Education, \\ University of South Africa, Pretoria \\ vwykmm@unisa.ac.za
}

Doi:10.5901/mjss.2014.v5n4p292

\begin{abstract}
Scholars are of the view that Afrocentricity as an educational, philosophical and theoretical paradigm. The purpose of this conceptual paper is to conceptualise and contextualize schooling in an inclusive education setting toward an Afrocentricindigenous pedagogy. The Afrocentric canons necessitates a more comprehensive approach that goes beyond questions of what is learnt, by whom, and how quickly it is learnt, to consider questions of howthe knowledge being disseminated is structured and applied particular to diverse and inclusive classrooms. Indigenous knowledge is often perceived as historical and ancient practices of the African peoples, which is a problematic perception of a Westernized view. Furthermore, the underlying principles, educational value, teaching principles underpinning indigenous pedagogy and the benefits of an Afrocentric-Indigenous Pedagogy for an inclusive classroom context is explained.
\end{abstract}

Keywords: Afrocentric-Indigenous Pedagogy, inclusive classroom, indigenous knowledge, indigenous pedagogy

\section{Introduction}

Scholars view Afrocentricity as an educational, philosophical and theoretical paradigm which can be use for any educational setting. This phenomenon is constructed and attributed to Asante's work. This particular phenomenon became a growing intellectual African scholarly voice in the 1980s as scores of African American and African scholars adopted an Afrocentric-Indigenous orientation to break away from the Eurocentric views on educational research. Afrocentricity is generally opposed to theories that "dislocate" Africans to the periphery of human thought and experience. From a research point of view, Asante argues that Afrocentricity can have a significant impact upon the way African scholars view their identity, specifically considering the African people as centred, located, oriented, and grounded. In other words, Afrocentricity meets the functional requirement identified as critical phenomenon embedded in schooling and inclusive education. The purpose of this conceptual paper is to conceptualise and contextualize schooling in an inclusive education setting toward Afrocentric-indigenous pedagogy. The Afrocentric canons necessitates a more comprehensive approach that goes beyond questions of what is learnt, by whom, and how quickly it is learnt, to consider questions of howthe knowledge being disseminated is structured and applied particular to diverse and inclusive classrooms. In the next paragraphs, the Afrocentric canons, underlying principles, educational value, teaching principles underpinning indigenous pedagogy and the benefits of an Afrocentric-Indigenous Pedagogy for an inclusive classroom context is explained.

\section{Afrocentric Learning Canons for an Inclusive Classroom}

Any acceptable approach to inclusive education requires a sufficiently comprehensive approach that addresses questions of how knowledge is being structured and used by educators and learners in an inclusive classroom setting. The application of the five Afrocentric canons, therefore, mandates that both learners and educators to consider the political, ideological, social, and cultural beliefs and motivations of all participants. This approach necessitates a more comprehensive approach that goes beyond questions of what is learnt, by whom, and how quickly it is learnt, to consider questions of how knowledge being disseminated is structured and applied in particular to diverse and inclusive classrooms. The suggested approach requires that all participants [educators, learners, parents, school management 
teams] be encouraged to be involved in searching for layers of subtext beyond what is actually revealed in texts and other discourses especially in the inclusive classroom (Florian and Black-Hawkins 2011; Shockley and Frederick 2010).

In the next paragraphs, several scholars provide an outline of the five Afrocentric canons in the context of inclusive education is discussed (Shockley and Frederick 2010; Kershaw 1992; Karenga 1988).

The concept of Ukweli, refers to the groundedness of educational processes and practices in the experiences of the learner in a particular school community being served. The experiences of learner and group members, therefore, should become the ultimate authority in determining what should be taught andhow it should be taught. In other words, the standards for establishing the educational needs of the learners, and the individuals in that inclusive classroom community, must be determined by the real life experiences of the learners and educators. The experiences of the classroom community must become the ultimate authority in determining what is needed by that learners and the teacher in the classroom. It is very important to establish that one cannot ignore the real life and historical experiences of educators and learners. This can be facilitated by the use off requent and current learner profiles by the teacher in an African context.Ukweli raise the issue of the subjectivity of truth. Of course, the question could be asked, justifiably, whether the "truth" as experienced by a particular community or individual hasmore validity than that experienced by any other. However, this question is easily answered since no school community or individual teacher has a monopoly on the truth as to which experiences are valid and therefore should count. Instead, each school community or individual involved in the teaching and learinng learning exercise can contribute a vital part of the truth, and all contributions must be taken into account.Ukweli, therefore, mandates that the creation of knowledge must be done within the context of the classroom community's own experiences. In the context of inclusive education all possible stakeholders, such as learners, educators, learning facilitators, the school community, and the wider societies must being included.

In the context of this paper, the second canon, utulivu, requires that the educational practitioner [teacher] should actively avoid creating, exaggerating, or sustaining divisions between or within classroom, but should instead strive to create harmonious relationships between and within the participating learners and groups in an inclusive classroom setting.In applying this canon, the specific issue of whether the consideration of an Afrocentric learning place was, in itself, a violation of the canon must be considered. Educators must strive for building harmonious relationships between and within learner groups and also expose them from analysing and exposing other learners to different scenarios in the class. While the interests' of learners must be considered, the educator has a greater responsibility to the broader society and especially to those who are intended as the victims of the disharmony.

The third canon, uhaki, requires a learning process that is fair to all learners, especially to those being served, and a process in which its applications are mindful of, and empathetic to, the welfare of all the participants. Fairness, in the context of this paper, and as defined bythis canon, must apply to all communities with a stake in the outcomes of the educational activity, that is, all stakeholders. Uhaki mandates that the educator be mindful of the interests and well being of the community being served. The interests of the community of learners should be paramount -this is simply a matter of justice. Application of uhaki also means that one cannot ignore the historical and social context in interpreting and reacting to any element of the learning process.In the context of university education, uhaki mandates that all learning materials include the perspectives of all groups making up a specific educational community. It also mandates that the learning material not cause harm to any group included in that community.

The fourth canon, ujamaa, requires that the facilitator reject the learner-facilitator/educator separation and not presume to be the well from which knowledge springs. It requires that knowledge and its dissemination should be informed by the actual and aspired interests of the community. The application of ujamaa should reveal the community affiliations of the participants, in addition to their own assumptions about the separation between learner and facilitator.

The final canon, kujitoa, requires that the researcher emphasize considerations of howknowledge is structured and used over the need for dispassion and objectivity. This empowers the participant to analyse and interpret the structure and use of text and other discourses, and to reveal the hidden assumptions embedded in such. That is, any acceptable process requires a sufficiently comprehensive approach that addresses questions of howknowledge is being structured and used. Participants must be aware that knowledge is inextricably bound into its social and political contexts.

In the next paragraph a discussion of indigenous knowledge is highlighted. These principles are very important and when planning your inclusive lesson in any way, keep it always in mind.

\section{What is Indigenous Knowledge?}

The definition of indigenous knowledge varies according to the diverse perspectives and life experiences of African scholars. According to Kincheloe (2006), indigenous knowledge refers to a multidimensional body of understandings that 
have, especially since the beginnings of the European scientific revolution of the 17th and 18th centuries, been viewed by European culture as inferior, superstitious, and primitive. Moreover, Mkabela and Luthuli (1997) argue that for indigenous people views indigenous knowledge is a lived world, a form of reason that informs and sustains people who make their homes in a local area. Indigenous knowledge is a bridge between human beings as communities of practice and their environments as natural settings for enabling learners to be empowering in indigenous knowledge and skills.

Based from the conceptualization of indigenous knowledge, the following is very important tenants in an inclusive teaching and learning context.

\section{Indigenous Knowledge as a Set of Values, Beliefs and Practices}

Indigenous knowledge (IK) is often perceived as historical and ancient practices of the African peoples, which is a problematic perception of a Westernized view. The word "indigenous" has often been used to refer to specific groups of people defined by ancestral territories, collective cultural configuration, and historical locations (Dei 2002 Gillian 2002). Moreover, indigenous knowledge is handed down from one generation to another through symbols, art, oral narratives, proverbs, and performance such as songs, storytelling, wise sayings, riddles, and dances (Dei 2002). In this context indigenous knowledge is a multifaceted bodies of knowledge, practices, and representations that are maintained and developed by peoples with long histories of close interaction with the local natural environment.According to Macedo (1999), the term indigenous, therefore, denotes that the knowledge is typical and belongs to peoples from specific places with common cultural and social ties. Throughout this chapter it is argue that indigenous knowledge is a process of learning and sharing social life, histories, identities, economic, and political practices unique to each cultural group. This reflects the uniqueness of ways that specific societies make meaning of the world and how such forms of knowledge address local problems and solutions that are context specific. In this chapter indigenous knowledge is framed as the complex set of activities, values, beliefs and practices that has evolved cumulatively over time and is active among communities and groups who are its practitioners. It remains so as long as long as the groups and communities who are its practitioners are committed to sustaining, creatively developing, and extending its potential enrichment within a specific setting.

\section{Indigenous Knowledge and Critical Pedagogy}

A relevant question is how can Afrocentric knowledge be used as a critical pedagogy to answer practical questions in education and bring about social change? Arguably, one of the penultimate goals of critical pedagogy is to make visible those marginal cultures that have traditionally been suppressed in Euramerican schooling (Giroux and McLaren 1986). For the Afrocentric-Indigenous teacher, Afrocentricity is a commitment to a pedagogy that is political education. It is a form of education intended to equip learners and educators with the requisite cultural capital to work toward the eradication of the structural conditions that marginalize the existence of certain segments of the school population. If education is to transform society, then it should be about getting learners and educators to work collaboratively and to "think critically, struggle against social injustices, and develop relations of community based on the principles of equality, freedom and justice.

The adoption of Afrocentric-Indigenous pedagogy by integrating critical pedagogy as an approach to educators' professional practiceis a logical progression as it shares the same philosophical roots as critical theory. As Giroux and McLaren (1986) stated that critical pedagogy argues that school practices need to be informed by a public philosophy that addresses how to construct ideological and institutional conditions in which the lived experience of empowerment for the vast majority of learners becomes the defining feature of schooling.

For example, in paper and in particular this text positioning the stance that to empower educators, learners and learners at school level to exercise critical views which raise questions about the relationships between the margins and centres ofpower in schools and are concerned about how to provide a way of reading history as part of a larger project of reclaiming power and identity, particularly as these are shaped around the categories of race, gender, class, and ethnicity in a particular society (Nakata et al. 2012; Shockley 2007).

\section{Educational Value of the Afrocentric-Indigenous Education}

The epistemological constructs of African peoples discussed in this paper have some practical relevance for the education of particularly youths of African descent. These constructs are ways of knowing and interacting within the 
African social world and environment. These constructs speak to African people's sense of the "meaning, and functioning of the universe and the natural context of their own existence . . . (as well as) . . . values, principles, and standards of ethics and morality" (Banks 1992). Ramose (2003) posit that the teachings of such ideas and values can help instil a sense of pride, self-worth, and self-esteem among learners and enable them to identify with and connect to the school.

Afrocentric education uses African culture and cultural values as a weapon of liberation and as counter knowledge to fight Euramerican ideological domination in the schools. Afrocentric education however must be more than emancipatory or liberatory pedagogy imbued with self-reflection, critique, and social action (Giroux and McLaren 1986). Several scholars argue that Afrocentricity as an intellectual paradigm focuses on addressing the structural impediments to the education of the African student by engaging her or hm to identify with her or his history, heritage, and culture. To be successful the Afrocentric pedagogue must move away from a manipulation of the "victim status and exploiting white guilt" to work toward finding solutions to pressing problems of educating learners of African descent (Graham 2007).

Ladson-Billings (2000) argues that it has been argued that the ideology of public schooling represented in official school curricula and academic discourses support dominating power relations that alienate many learners from the school system. The public school system thus far has failed to respond adequately to the needs of the African student. It is generally acknowledged that one of the most crucial issues facing North American educational system is the "dropout problem" and low academic achievement of particularly poor, disadvantaged, and some visible minority learners. Moreover, Lee (2005) concur that many African parents and educators have become increasingly concerned about the dropout problem and the effects on their communities. Parents are concerned for what they see as the schools' inability to educate their children.

In the current South African school system, the average black learners academically perform below white learners. Research reflected that there is an urgent need for a critical analysis of the institutional power structures within which learning, teaching, and administration of education is taken place, specially schools whereby black youths are marginalized, excluded, and alienated (Ramose 2003; Ladson-Billings 2000). The current processes of schooling undermine black learners' subjectivities and their lived experiences whether as poor, middle class, male, female, single parent, immigrant, or African born. For many learners the marginalization and the delegitimation of their individual and collective experiences all contribute to their low self-worth and self-esteem. This in turn adds to their frustrations and alienation from many societal institutions and, consequently, the tendency to rebel through oppositional behaviors like "dropping out."

Murrell (2002) is of the view that learners of African descent must see themselves represented in all aspects of the inclusive education system. This means our schools have to incorporate Africa-centered perspectives in the strategies of learning, teaching, and administration of education of black youths. For example, an Afrocentric curriculum can link the schooling of youths to the traditions and histories of African peoples and provide learners with a sense of voice and relationship to others. Afrocentricity-as an alternative, non exclusionary intellectual paradigm for educating black youthsrequires a pedagogical approach that centers the black student in the discussion and analysis of the events that have shaped human hstory and development.This way black youths see themselves as subjects rather than as objects of education. They can easily identify with the materials being taught discussed in class and would be in a stronger position to learn. Learners must be the active generators of their own knowledge. For the African youth, Afrocentricity as a discursive practice can offer "a language of possibility" (Ramose 2003; Giroux and McLaren 1986) through which to deconstruct and reclaim, not only new forms of knowledge, "but also provide new ways of reading history through the reconstruction of suppressed memories that offer identities with which to challenge and contest the very conditions through which history, desire, voice and place are experienced and lived" (Giroux and McLaren 1986).

In the section of the paper IK is conceptualized, and argue as a process of learning and sharing social life, histories, identities, economic, and political practices unique to each cultural group in the context of inclusive education

\section{Teaching Principles Underpinning Indigenous Pedagogy}

The indigenous pedagogy (IP) is a distinctive phenomenon which focuses on four relevant respects for promoting Indigenous knowledge. First, IK pedagogy privileges knowledge rooted in oral traditions flowing through the complex authority of Elders over book knowledge. Today this is emphatically the case concerning knowledge about the sacred, especially in light of cultural dispossession and appropriation. Perhaps it is not surprising that one finds broadly in indigenous communities a hermeneutic of suspicion (if not dismissal) applied to many formulations of tradition in texts, even those of IKP authorship. Knowledge of and stories about the past in lived moments of oral exchange are never simply locked up in bygone eras: they become tangible realities that create a felt relationship with the past that cannot 
easily be engendered in histories that are written and read alone (Nakata et al. 2012; Shockley 2007).

Secondly, IK pedagogy couples the knowledge taught and learned about tradition with responsibility on the part of both teacher and learner to use that knowledge on behalf of community well-being. Here the orality of privileged cultural exchange ensures that stewards of cultural knowledge can exercise considerable control over who learns of it, how and in what contexts they shall learn it, and what expectations accompany the passing on of knowledge. Here is a kind of structure of intellectual sovereignty the value of which has been accentuated in light of challenges to political and other kinds of sovereignty.

Thirdly, IK pedagogy engineers firsthand learning situated in and implicated in a student's experience, at the direction of but not determined by the authority of the Elder. Indigenous people children are refreshingly, boisterously present in every ceremonial and other community occasionally experienced. They are taught skills of active watching and listening, not simply the content of what to look or listen for. They are taught to take in cultural lessons experientially, to take them in over time, and to not expect spoon feedings of segmented units of knowledge. Until we developed more discerning appreciations of such things,took teacher andother traditional Elders to be "passive" educators. Althoughwe assert this without benefit of what trust as a rich body of scholarshipon educational psychology,people claim knowledge derived experientiallyis deeper in some way. What is more, the knowledge they claimis less likely to become ossified by ideological orthodoxies (Norman 2004).

Finally, IK pedagogy makes room for holistic reflection that engenders synthesis across the putative boundaries of a modern Western sociology of knowledge: those differentiating religion from politics, economics, medicine, art, and history, and differentiating knowledge about"religion" from the spiritual experience and ethical concerns that surround it (Tejeda et al. 2002). Here the situational and relational nature of the oral flow of cultural knowledge, as well as the stressed link between cultural learning and community well-being, to which already alluded,defy lessons that are easily categorized according to the differentiated fields of inquiry andpractice in the modern West. Learning herbal knowledge, for example,I nvolves plant biology,ecology, physiology, psychology, and some familiaritywith the historical, economic, and social causes of illness, not tospeak of appropriate ritual prayers and rehearsal of sacred narratives.

\section{Eight Framework Strategy of Afrocentric-Indigenous Pedagogy}

In this part of the conceptual paper, the researcher content that for an inclusive classroom particulars from an Afrocentric perspective one or more of these strategies could be the triggers for an Afrocentric-Indigenous Pedaoggy. The identified eight framework of Afrocentric-Indigenous Pedagogy brings indigenous ways of knowing and being 'out of the dusty corners of anthropology and linguistics' and into the inclusive classroom (Nakata et al. 2012; Shockley 2007; Ramose 2003). It comprises eight interconnected pedagogies that see teaching and learning as fundamentally holistic, non-linear, visual, kinaesthetic, social and contextualised. If African teachers use these eight framework strategies as pedagogical tools to strengthening their praxis and therefore advance an inclusive education as change agents for quality education for all. In the next paragraphs, each strategy is explained for the purpose of this paper.

\subsection{Storytelling and sharing strategy:}

Story telling is a key pedagogical tool in the eight-way framework as a narrative based one of story sharing. This is fundamental to the eight ways as it is not only the way indigenous people keep abreast of current issues in an oral culture but is also the way they manage their dynamic but eternal connection to environment. Yarning is how indigenous people transmit knowledge and learn about the world Most African communities, 'elders teach using stories, drawing lessons from narratives to actively involve learners in introspection and analysis'. This is not monologic but a shared dialogue with learners; hence teaching and learning is also a social activity in Afrocentric-Indigenous pedagogy.

\subsection{The deconstruct - reconstruct strategy:}

This strategy is a holistic, global orientation learning whereby the initial focus is on the whole rather than the parts 'seeing an overall meaning, purpose and structure first and then breaking itdown into manageable chunks'. In thispedagogy, the text is initially modelled by the more knowledgeable otherbefore the learner tries it independently; thus watching first then doing. 


\subsection{The non-linear strategy:}

According to indigenous pedagogy learning is not sequential but a continuous relational endeavour. Problems are solved laterally through association andthrough making connections with existing knowledge. Hence,there is much 'repetition and returning to concepts for deeper understanding'

\subsection{Environment issues strategy:}

'Afrocentric-Indigenous pedagogies are intensely ecological, place-based and drawn fromthe living landscape within a framework of profound ancestral and personal relationships with place. Forindigenous people, learning is about linking content to local land and place and is thus highly contextualised.

\subsection{Community involvement strategy:}

Learning according to aboriginal pedagogy is group-oriented, localised andconnected to real-life purposes and contexts. The motivation for learning is inclusion in the community, while teaching refers to community life and values'

\subsection{Experiential Learning strategy:}

This way of learning is to visualise pathways of knowledge. Diagrams orvisualisations are used to map out processes explicitly for the learner. In optimal Aboriginal pedagogy, the teacher and learner create a concrete, holistic image of the tasks to be performed which serves as a reference point for the learner.

\subsection{Symbolic and metaphors strategy:}

This pedagogy uses images and metaphors to understand concepts andcontent. Knowledge is coded in symbols, signs, images and metaphors and istherefore a tool for learning and memorizing complex knowledge.In an AfrocentricIndigenous pedagogy, learning through maps and symbols andimages strategies are naturally linked; 'one provides the structure ofmemory while the other provides the language of memory'.

\subsection{Silence and ody language strategy:}

Perhaps also not surprisingly, Afrocentric-Indigenous pedagogy is kinaesthetic, hands-on-learning with a strong emphasis on body language and silence.According to this strategy non verbal pedagogy 'ismore than just the idea of reduced language, learners testknowledge non-verbally through experience, introspection and practice,thereby becoming critical thinkers who can judge the validity of new knowledge independently'.

\section{Advantaes of the Afrocentric-Indigenous Pedagogy for an Inclusive Classroom Context}

Several literature reviews indicated that this concept holds advantages for the inclusive classroom (Pellerin 2012; Andersen 2012; Norman 2004). The following are some advantages:

\subsection{Learners frequently return to learnt knowledge}

Apart from the overlaps already mentioned, which are clear advantages, eight strategy frame way's orientation is non linear so learners frequently return to learntknowledge. I see this also as an advantage, as it allows for deeper understanding and introspection. Criticism of western pedagogy is that it isbecoming too linear with focus on standardised testing at the expense of other skills.

\subsection{Promote introspection, reflection and other types of self-directed learning}

In comparison to Afrocentric-Indigenous pedagogy, western pedagogy 'ignores indigenous peoples' knowledge that comes from introspection, reflection and other types ofself-directed learning'. Surely an important part of any learning is 
being ableto reflect on what and how one learnt.

\subsection{Learners are expose to contextualised learning}

In addition, eight-ways place-based learning allows for more contextualisedlearning.this allowsstudents to see how education is relevant to and meaningful in their own lives.

\subsection{Learners are aware of lesson outcomes and expectations}

A further advantage is their explicit mappings of course tasks/materials solearners are aware of where the lesson or unit of work is going and what isexpected. Criticism of western pedagogy, particularly in the area of literacy, isthat some skills are now being taught too implicitly. The eight-way framework as totally adaptable and can easily integrate into western pedagogy and therefore expose learners to different ways and ideas into the mainstream classroom.

The eight frame strategy show 'amazing' outcomes in terms of engagement and higher order thinking. Learners became more focused and were enthused by using indigenous pedagogy. In addition, the eight frame strategy enhance positive shift in behaviour, attitude, relationships and quality of learners work specially for an inclusive education context.

\section{Conclusion}

The present school system is monocultural. Afrocentrists aim to expand the curriculum to include the valid achievements and knowledges of all societies and to use the voice of the community/culture itself to present a people's histories and struggles for affirmation. The Afrocentric education is build on seven fundamental constructs. Indigenous knowledge is a process of learning and sharing social life, histories, identities, economic, and political practices unique to each cultural group. This reflects the uniqueness of ways that specific societies make meaning of the world and how such forms of knowledge address local problems and solutions that are context specific. In this chapter indigenous knowledge is framed as the complex set of activities, values, beliefs and practices that has evolved cumulatively over time and is active among communities and groups who are its practitioners. Several fundamental constructs underlying the Afrocentric approach for an inclusive classroom setting is highlighted. This phenomenon has specific educational values and practical relevance for the inclusive education. There are important teaching principles underpinning AfrocentricIndigenous pedagogy. This is discussed in the eight-strategy framework of Afrocentric-Indigenous Pedagogy as well the advantages for an inclusive classroom. Furthermore, the role of the teacher in using Afrocentric-Indigenous Pedagogy in the inclusive classroom is explained. An Afrocentric - Indigenous Pedagogy frame for an inclusive education context to support and enhance teacher professional development to effect change in classroom. Lastly, reflecting on the role of the teacher and communities in promoting and supporting the idea of Afrocentric-Indigenous education for inclusivity.

\section{References}

Andersen C. 2012. Critical Indigenous Studies in the classroom: Exploring the local using primary evidence. International Journal of Critical Indigenous Studies, 5(1), 67-92.

Asante M. 1991. The Afrocentric idea in Education.Journal of Negro Education,60:170-179.

Banks W C. 1992. The theoretical and methodological crisis of Afrocentric conception.Journal of Negro Education, 61 (3), 262-272.

Dei G J S. 2002.Afrocentricity: A Cornerstone of Pedagogy. Anthropology andEducation Quarterly 25(1):3-28.

Florian L, Black-Hawkins K.2011. Exploring inclusive pedagogy. British Educational Research Journal 37(5): 813-828

Gillian A. 2002. Participation and power. Africa Insight, 32(1), 25-29.

Giroux HA, McLaren P. 1990. Critical Pedagogy and Rural Education: A Challenge from Poland.Peabody Journal of Education 67( 4):154-165

Graham LJ. 2007 (Re)Visioning the Centre: Education reform and the 'ideal' citizen of the future, Educational Philosophy and Theory, 39:2, pp. 197-215.

Karenga M. 1988. Black studies and the problematic of a paradigm: The philosophical dimension. Journal of Black Studies, 18(4), 395414.

Karenga M. 1993. Introduction to Black studies. Los Angeles: The University of Sankore Press.

Kershaw T. 1992. Afrocentrism and the Afrocentric method. Western Journal of Black Studies, 16(3), 160-168.

Kincheloe J. 2006. Critical ontology and indigenous ways of being: Forging a postcolonial curriculum. In Y. Kanu (Ed.), Curriculum as cultural practice (pp. 181-202). Toronto, Canada: University of Toronto Press.

Ladson-Billings G. 2000. Fighting for our lives: Preparing teachers to teach African American students. Journal of Teacher Education, 
51, 206-214.

Lee C D. 2005. The state of knowledge about the education of African Americans. In J. King (Ed.), Black education: A transformative research and action agenda for the new century (pp. 45-73). Washington, DC: American Educational Research Association.

Macedo D. 1999. Decolonising Indigenous knowledge. In L. Semali \& J. Kincheloe (Eds), What is Indigenous Knowledge, (pp. xi-xvi). New York: Falmer Press.

Mazama A 2001. The Afrocentric Paradigm: Contours and Definitions. Journal of Black Studies, 31(4): $387-405$ From http://www.jstor.org/page/info/about/policies/terms.jsp

Mkabela NQ, Luthuli P C. 1997. Towards an African philosophy of education. Pretoria, South Africa: Kagiso Tertiary.

Murrell, P. C. (2002). African-centered pedagogy: Developing schools of achievement for African American children. Albany: State University of New York Press.

Nakata NM, Nakata V, Keech S, Bolt R. 2012. Decolonial goals and pedagogies for Indigenous studies Decolonization:Indigeneity, Education \& Society, (1) 1::120---140

Norman H. 2004. Exploring effective teaching strategies: Simulation case studies and Indigenous Studies at the university level. Australian Journal of Indigenous Education, 33, 15-20.

Pellerin M. 2012. Benefits of Afrocentricity in Exploring Social Phenomena: Understanding Afrocentricity as a Social Science Methodology The Journal of Pan African Studies, 5(4):149-160

Ramose MB. 2003 Transforming Education in South Africa: Paradigm shift or change?, South

African Journal of Higher Education, 17:3, pp. 137-143.

Shockley KG . 2011. Reaching African American Students: Profile of an Afrocentric Teacher Journal of Black Studies 42(7) 1027-1046 http://jbs.sagepub.com/content/42/7/1027

Shockley KG, Frederick RM. 2010. Constructs and Dimensions of Afrocentric Education. Journal of Black Studies, 40(6):1212-1233

Shockley K. 2007. Literatures and definitions: Toward understanding Africentric education. Journal of Negro Education, 76(2), $103-117$.

Tejeda C., Espinoza M, Gutierrez K. 2002. Toward a decolonizing pedagogy: Social justice reconsidered. In P. Trifonas (Ed.), Pedagogies of difference: Rethinking education for social change (pp. 10-38). New York: Routledge. 